\title{
Artigo
}

\section{Doping e controle de feminilidade no esporte*}

\author{
Viviane Teixeira Silveira ${ }^{* *}$ \\ Alexandre Fernandez Vaz ${ }^{* * *}$
}

\section{Resumo}

Neste artigo ocupamo-nos das relações entre doping e o corpo e a sexualidade de mulheres atletas. A partir da análise da Política de Verificação de Gênero no esporte, bem como de um episódio recente com a atleta Caster Semenya, refletimos sobre a relação que o doping tem com os discursos generificantes, mostrando que a preocupação com as mulheres atletas dopadas pressupõe uma inquietação com suas identidades sexuais e de gênero.

Palavras-chave: Esporte, Gênero, Doping.

* Recebido para publicação em 20 de junho de 2012, aceito em 10 de março de 2013.

** Doutora em Ciências Humanas/UFSC. Professora da Universidade do Estado de Mato Grosso/UNEMAT. vivianeteixeirasilveira@gmail.com

*** Professor adjunto do Centro de Ciências da Educação assim como do Programa de Pós-Graduação em Educação e do Doutorado Interdisciplinar em Ciências Humanas da Universidade Federal de Santa Catarina/UFSC. alexfvaz@uol.com.br 
448 Doping e controle de feminilidade no esporte

Doping and Control of Womanliness in Sport

\begin{abstract}
This paper reflects about relations between doping and sexuality by women athletes. Taking in account the Gender Politic Analysis in Sport and the case of the runner Caster Semenya, the paper put in question doping and genders discourses, in sense of suggesting that that relation supposes an inquietude with sexual and gender identities
\end{abstract}

Key Words: Sport; Gender; Doping 
Em 2009, após a atleta sul-africana Caster Semenya ser submetida ao teste de feminilidade, "uma casa noturna de striptease na África do Sul, tentou se aproveitar da polêmica criada em torno da sexualidade da atleta e criou um anúncio em um outdoor com uma mulher semi-nua deitada sobre o slogan "não precisa de teste de sexualidade" (Boate... 1/10/2009). ${ }^{1}$ O proprietário do estabelecimento tentou justificar seu oportunismo: "Queremos somente garantir aos nossos clientes que não temos mulheres hermafroditas já que isso é tão comum na indústria do entretenimento adulto" (Boate... 1/10/2009); como resultado, o dono foi multado. "Al verla de cerca es como un hombre. Parece cien por cien masculina, todo, la cara, el cuerpo, la manera de correr, la forma de moverse... Tiene todo para ser un hombre" (Mayte... 20/08/2009) ${ }^{2}$, disse Mayte Martínez, adversária de Caster na prova de $800 \mathrm{~m}$, ao ser perguntada sobre o assunto.

Neste artigo, ocupamo-nos das relações entre doping e o corpo e a sexualidade de mulheres atletas. Os excertos acima abrem caminho para apresentar as questões que percorreremos. Buscamos, inicialmente, demonstrar a relação do surgimento dos hormônios sintéticos e a utilização do doping no esporte, entendendo-o como uma tecnologia química que atua na performance atlética.

Num segundo momento, refletimos sobre a relação que o doping tem com os discursos generificantes, mostrando que a preocupação com as mulheres atletas dopadas pressupõe uma inquietação com suas identidades sexuais e de gênero. No esporte de alto rendimento, o gênero $e$ a identidade de gênero são construídos sobre o corpo (Ann Lock, 2003). Esse é um território de negociação entre homens e mulheres, expressão da forma como

\footnotetext{
${ }^{1}$ Disponível em: <http://esportes.terra.com.br/atletismo/noticias/0,,OI4015515El15503,00-

Boate $+e+$ multada + por + ironizar + sexualidade + de + Semenya $+e m+$ anuncio.html >. Acessado em: 13/07/2010.

2 Disponível em: <http://www.marca.com/2009/08/20/atletismo/1250772526.html>. Acessado em: 10 mar 2012.
} 
se exibe um determinado tipo de feminilidade e/ou de masculinidade e, portanto, da identidade de gênero de um/a atleta (Bordo, 1993; Connell, 1987, 1999, 2002; Markula, 2003).

Em seguida, analisamos a Política de Verificação de Gênero no esporte, entendendo-a como parte de uma estratégia para a manutenção do campo esportivo como um espaço generificado, mas, também, como uma forma de controlar a utilização do doping, depois que esse artifício assumiu proporções incontroláveis com o advento da indústria fármaco-química. A fim de exemplificarmos o emprego dessa política, trazemos um episódio ocorrido com uma atleta de alto rendimento esportivo, a sul-africana Caster Semenya.

Ao retomarmos a crítica à condenação ao doping como artificialismo e às políticas generificantes que a ele se associam, utilizamos um conjunto de discursos oficiais - da Federação Internacional e da Confederação Brasileira de Atletismo (IAAF e CBAt), bem como do Comitê Olímpico Internacional (COI) associados à construção do sexo, do gênero e da sexualidade das atletas. Também consideramos discursos da imprensa sobre o episódio Semenya, não exatamente como fontes, mas como referências que podem ajudar a pensar significados que nem sempre vão ao encontro dos discursos oficiais apresentados.

\section{Da manipulação dos hormônios ao doping esportivo}

Com a expansão da indústria fármaco-química das últimas décadas, a manipulação dos hormônios e a criação dessas substâncias na forma sintética, uma nova gestão política e técnica do corpo, do sexo e da sexualidade, encontra lugar. Segundo Preciado (2008), sexo e gênero não são mais os mesmos após tal crescimento, uma vez provocada a tecno-fabricação dos corpos sexuados que, por sua vez, são também pressupostos para essa indústria.

A criação da pílula anticoncepcional à base de estrógeno sintético, em 1946, demarca um novo momento para a indústria fármaco-química, que entra na era hormonal com esse que se 
torna um dos medicamentos mais utilizados na história da humanidade. Em 1958, na antiga União Soviética, ocorre a primeira faloplastia (cirurgia de construção de um pênis a partir de enxertos de tecidos de pele), parte do processo de mudança de sexo de mulher para homem (Preciado, 2008), mostrando que já de longa data o desenvolvimento biotecnológico investe nas possibilidades de intervenção para a construção de um sexo $e$, não somente, de um corpo. ${ }^{3}$

A partir de 1966, surgem os antidepressivos que atuam diretamente na síntese da serotonina; em 1987, a fluoxetina começa a ser comercializada com vários nomes, dentre os quais, o mais famoso é o Prozac. Nos anos 1980, descobrem-se e comercializam-se diversos hormônios, como o GH (hormônio do crescimento) e o DHEA (dehidroepiandrosterona), bem como numerosas substâncias anabolizantes que serão utilizadas na medicina e, legal ou ilegalmente, no esporte. Desde o final do século $\mathrm{XX}$, uma grande quantidade de crianças vem sendo medicada com ritalina, utilizada para o tratamento de transtornos de déficit de atenção (Morton, Stockton, 2000). Vemos nascer uma sociedade na qual a presença e a utilização de drogas dos mais diferentes tipos fazem parte tanto da vida de uma atleta, quanto de pessoas em tratamentos médicos convencionais. Preciado (2008:33) sugere que "el éxito de la tecnociencia contemporánea es transformar nuestra depresión en Prozac, nuestra masculinidad en testosterona, nuestra erección en Viagra, nuestra Sida en triterapia".

Para Preciado, um bom exemplo de compreensão do que ela nomeia como atual regime fármaco-pornográfico ${ }^{4}$ é a relação entre esporte e prostituição. A autora cita a Copa do Mundo de

\footnotetext{
${ }^{3}$ A primeira cirurgia de redesignação sexual oficialmente comunicada aconteceu em 1952, na Dinamarca (Chiland, 2008).

4 Segundo Preciado (2008), a expansão da indústria fármaco-química e a questão semiótica-técnica da subjetividade sexual, formam o regime fármacopornográfico. Para essa autora, o gênero é um dos produtos fármacopornográficos (fármaco $=$ corpo, pornô $=$ representação) que têm sido fabricado com mais êxito pela indústria farmacêutica e de comunicação nos últimos tempos.
} 
Futebol de 2006, quando o governo alemão teria incentivado a criação do Artemis, enorme prostibulo situado muito próximo ao Estádio Olímpico de Berlim. Trabalhadoras do sexo migraram de vários lugares do mundo para lucrar no imenso prédio com piscinas, saunas e quartos em número suficiente para atender, em média, 600 clientes por dia. Sexo é um esporte relacionado a uma rede de expressão do corpo sexualizado $e$ ao universo das drogas e hormônios sintéticos do tráfico internacional (Preciado, 2008). ${ }^{5}$

Segundo Haraway, "somos todos quimeras, híbridos teóricos e fabricados - de máquina e organismo; somos, em suma, ciborgues" (2000:41), utilizando os aparatos tecnológicos que estão a nosso dispor. Já não estaria claro onde termina o humano $e$ começa a máquina: "não existe, em nosso conhecimento formal, nenhuma separação fundamental, ontológica, entre máquina $e$ organismo, entre técnico e orgânico." (Haraway, 2000:100). Dessa forma, a imagem do ciborgue pode contribuir para rompermos com o dualismo corpo - natureza para a explicação dos corpos e suas expressões. Ser ciborgue refere-se também à frequência em academias de ginástica, à utilização de suplementos alimentares, roupas específicas, "inteligentes" e aerodinâmicas, e quaisquer aparatos que visem uma melhoria ou alteração na máquina humana. Nessa perspectiva, o doping pode ser entendido como uma tecnologia química a serviço do espetáculo, pois atua diretamente na performance atlética.

A descoberta da testosterona sintética e dos esteroides anabolizantes adentra, com a expansão da indústria fármacoquímica, o campo esportivo para incrementar as performances, $e$ esse passa a ser palco dos mais recentes investimentos

${ }^{5}$ A relação entre esporte $e$ prostituição pode abrir caminhos para compreendermos o atual regime fármaco-pornográfico: "En lugar de imaginar la prostitución como una práctica al margen de la industria del fútbol, habría más bien que considerar el deporte en general y el fútbol en particular como parte de una industria farmacopornográfica planetária que controla redes de Internet, clubes, discotecas, cadenas de producción, distribución y difusión pornográfica, industrias farmacêuticas de producción y tráfico de drogas anabolizantes y de otras moléculas que suplementen el cuerpo deportivo y sexual..." (Preciado, 2008:192). 
tecnológicos e procedimentos de manipulação hormonal. O esporte de alto rendimento é uma prática profissionalizada $e$ comercializada, na qual a meta de maximização do desempenho é perseguida com obstinada determinação pelas atletas, e os meios para atingir os melhores resultados mundiais foram autorizados a expandir progressivamente para os limites do que é cientificamente (im)possível (Beamish; Ritchie, 2004).

No campo esportivo, esses investimentos podem ser observados em grandes eventos, como os Jogos Olímpicos. Às teorias e práticas do treinamento esportivo se somam as intervenções modernas da ciência e de campos outrora desconhecidos para o esporte, tais como o doping genético, a nanotecnologia (fabricação de dispositivos moleculares) e a biotecnologia (manipulação dos elementos dos seres vivos, incluindo o DNA - código genético) ${ }^{6}$

Pesquisas recentes ${ }^{7}$ sugerem que, em uma época próxima, a criação de atletas geneticamente modificados será possível, levando à fabricação de corpos nos quais o resultado dos processos será sempre mais detalhado e sofisticado. O livro "Atletas geneticamente modificados", do filósofo Andy Miah (2008), traz uma interessante proposta de reflexão sobre a questão da ética no esporte de alto rendimento, diante de recentes descobertas sobre o funcionamento e a potencialidade do genoma humano. $\mathrm{O}$ autor discute as possibilidades de performances esportivas, sem condenar ou defender as tecnologias de modificação genética, mas propondo várias alternativas de pensamento sobre os dilemas e desafios que deverão surgir em função desse novo campo associado aos esportes e suas relações com o corpo e a própria condição de ser humano.

O doping é um elemento constitutivo do esporte moderno $e$ produto da ciência, relacionando-se diretamente com outras

\footnotetext{
6 Para aprofundar esse assunto, consultar Artioli (2007).

7 Para saber mais sobre o debate acerca dos investimentos de pesquisas genéticas $e$ atletas, consultar os sites <www.genome.gov> $e$ $<$ www.genomenewsnetwork.org $>$.
} 
práticas e tecnologias que expandem os limites do desempenho humano, mas que são, arbitrariamente, vinculadas ao "puro", "natural" e "autêntico", e que não se apresentam contra as suas regras. Essa é uma questão bastante controversa, afinal, a utilização de drogas no esporte de alto rendimento parece ser imprescindível para que ele continue existindo como espetáculo lucrativo e espetacular. Além disso, não existe algo "natural" no que se refere à relação com o corpo $e$ o treinamento. Dadas as enormes exigências competitivas $e$ os intensos sacrifícios físico $e$ psicológico aos quais as atletas são submetidas durante os treinamentos e competições, francamente prejudicais à saúde, como ser tão peremptório na condenação do doping? Segundo Vaz (2005).

\begin{abstract}
O doping parece basear-se, nesse sentido, na ideia de que o organismo humano é um mecanismo complexo manipulável tecnicamente, e que os comportamentos $e$ experiências humanas podem ser "melhorados" para além das aptidões tradicionais, tanto do ponto de vista físico quanto intelectual ou mesmo emocional. Mas essa é a lógica do treinamento corporal, de seus princípios $e$ métodos, que pouco ou nada têm de "naturais" (Vaz, 2005:33).
\end{abstract}

Outra controvérsia em torno do uso de doping no esporte é a relação com as drogas consideradas de uso recreativo. A cocaína (benzoilecgonina) e a maconha (cannabis) são frequentemente encontradas em testes antidoping, evidenciando $\mathrm{o}$ que especialistas da Comissão Médica do COI denominam de problema do uso de drogas sociais pelos atletas, e alertando para a importância da imagem dos esportistas na sociedade (De Rose et al., 2004). Esta última preocupação explica por que drogas como a cocaína e a maconha são consideradas esportivamente ilegais, mesmo quando utilizadas em períodos fora de competição.

O uso de drogas é condenado com frequência, em nome de uma moral que se empenha em reafirmar o princípio de igualdade formal de chances no esporte, sendo tal prática interpretada como 
violação e traição ao caráter "puro" que teriam as práticas esportivas (König, 1995). O argumento sobre o uso de recursos "naturais" para a melhoria da performance atlética anda lado a lado com a defesa da saúde das atletas (mesmo considerando que elas não procuram a melhoria de seus indicadores de saúde ao se dedicarem à competição), e também por isso há uma condenação ao doping.

Tomamos a relação que o doping tem com os efeitos de masculinização das mulheres atletas para atentar sobre o questionamento da feminilidade e sua interdependência com o corpo e a sexualidade. O fio condutor de nossa reflexão é desenvolvido pela hipótese de que o doping das mulheres atletas perturba a matriz heterossexual por romper com o trinômio sexogênero-sexualidade (Butler, 2003).

Até o presente momento apresentamos o doping como uma tecnologia fármaco-química que está a serviço do esporte de rendimento para a produção de performances mais velozes, fortes $e$ espetaculares. A seguir, mostraremos a relação constituída historicamente entre discursos generificantes e a utilização de doping no campo esportivo, mostrando como o uso de substâncias proibidas foi, pouco a pouco, relacionando-se a discursos sobre o corpo, sexo e sexualidade das mulheres atletas.

\section{Discursos generificantes e doping}

Com o crescimento do uso de fármacos no cenário esportivo, principalmente de esteroides anabolizantes, sobre as mulheres também recai um olhar vigilante. A partir dos Jogos Olímpicos do México, em 1968, quando uma mulher é flagrada com algum indício corporal de que poderia ter ingerido substâncias proibidas (crescimento de pelos, engrossamento da voz, diminuição dos seios, musculatura muito desenvolvida, amenorreia), passava a ser suspeita de doping e, além disso, sua identidade de gênero e sexual ${ }^{8}$ era questionada, tendo como pano

8 Os sujeitos se identificam, social e historicamente, por meio das relações sociais $e$ das redes de poder de uma sociedade, como masculinos e/ou femininos $e$, 
de fundo uma questão moral. Ter um corpo que não promovesse os valores estéticos de uma feminilidade heterossexual ou que apresentasse falta de feminilidade era (e é) associado a noções estereotipadas de lesbiandade. ${ }^{9}$

No cenário esportivo, as mulheres têm sido objeto de acusações de virilidade e lesbiandade (Cahn, 1994; Griffin, 1998), demonstrando que a identidade sexual está estreitamente ligada à de gênero e ambas atravessam a cultura esportiva por meio do corpo. Além de perguntas sobre a sexualidade, as mulheres atletas estão sujeitas a uma sexualização normativa e a uma intensa pressão para se conformarem a uma aparência feminina (Messner, 2002). O uso da etiqueta de lésbica tem servido como um ataque às mulheres atletas que possuem uma aparência física e/ou performance esportiva que fuja do padrão heteronormativo. Essas mulheres são questionadas quanto ao seu status biológico, ou seja, atletas que tenham uma performance excepcional precisam comprovar que verdadeiramente são mulheres (Kane, 1995).

Relacionamos a utilização de substâncias químicas à produção de um corpo atleta (doping feminino) por considerar que a presença corporal que foge do padrão heterossexual feminino representa uma ameaça à ordem social dominante. A utilização do doping pelas atletas causa incômodo, principalmente, pelos efeitos que essas substâncias podem ter sobre a feminilidade convencional, que passa a ser relacionada diretamente com o efeito de masculinização.

dessa forma, constroem suas identidades de gênero que não necessariamente vão ao encontro de suas identidades sexuais. $\mathrm{O}$ modo como a pessoa se percebe em sua orientação sexual e o modo como ela torna pública (ou não) essa experiência de sexualidade é que constitui as identidades sexuais dos sujeitos (homossexual, heterossexual, ou bissexual).

9 Ann Lock (2003) afirma que na imprensa popular as atletas acusadas de doping ou aquelas que não passam nos testes são questionadas pelo seu tamanho, em termos de musculosidade, e comparadas aos homens. Esses insultos de feiura e/ou virilidade questionam a autenticidade dessas mulheres que são (presumivelmente) acusadas de lésbicas. 
As preocupações com a masculinização das mulheres atletas são uma problemática contemporânea, mas que começou e se intensificou durante a Guerra Fria. A participação das mulheres no esporte no Leste Europeu foi mais promovida que nas nações do Oeste, pois era vista como parte de um projeto de mudança social, mantido pelos líderes da política de Estado (Guttmann, 1984). As nações soviéticas enfatizaram a importância da atividade física $e$ dos esportes para os desenvolvimentos humano e cultural, transformando-os em uns dos vetores mais efetivos da disputa entre o capitalismo e o socialismo realmente existente. Segundo Schmolinsky (1982), importante treinador alemão do Leste, em manual destinado à preparação de atletas,

\begin{abstract}
embora as práticas atléticas sirvam hoje objectivos fundamentalmente diferentes dos de outrora, não devemos pensar que não se ligam à ordem social sob a qual são exercidas. Não são, como fenómeno social, de interesse secundário - antes são conscientemente postas ao serviço dos objectivos políticos e dos interesses culturais da classe dominante: $e$ isto em todos os países (1982:17).
\end{abstract}

As mulheres acabaram exercendo um papel importante na consolidação do bloco organizado sob o Pacto de Varsóvia, com nações ao redor da URSS, mostrando sua potência no mundo esportivo e sendo utilizadas como instrumento de propaganda ideológica. Os corpos atletas das mulheres comunistas estavam a serviço de suas nações ao buscarem o êxito esportivo internacional. Por muito tempo, a propaganda comunista por meio do esporte vigorou na celebração de atletas fortes $e$ musculosas, heroínas e ícones dos países do Leste Europeu (Lenskyj, 2008).

Bordo (1993) sugere que os músculos simbolizam a força e a masculinidade e são diretamente associados aos homens, não sendo vistos como atributos femininos. $\mathrm{O}$ ideal de corpo feminino no contemporâneo não seria apenas magro, mas também moderadamente tonificado e bem torneado. $\mathrm{O}$ inevitável aumento dos músculos resultante do treinamento 
atlético acaba trazendo um desacordo com tal ideal, denominado pela autora de "peso insustentável".

Dessa forma, quem desenvolve músculos e força enfrenta o risco de virilização e da masculinização. Podemos sugerir que essa preocupação com uma masculinização da mulher atleta vise um controle da heteronormatividade no esporte para que não se rompa a matriz heterossexual sexo-gênero-sexualidade, definida por Butler (2003), promovendo uma ordem esportiva claramente heterossexual. A heterossexualidade para o sexo feminino acaba sendo expressa em uma performance de feminilidade. Segundo a autora,
gêneros "inteligíveis" são aqueles que, em certo sentido, instituem e mantêm relações de coerência e continuidade entre sexo, gênero, prática sexual e desejo. Em outras palavras, os espectros de descontinuidade e incoerência, eles próprios só concebíveis em relação a normas existentes de continuidade e coerência, são constantemente proibidos $e$ produzidos pelas próprias leis que buscam estabelecer linhas causais ou expressivas de ligação entre o sexo biológico, o gênero culturalmente constituído, e a "expressão" ou "efeito" de ambos na manifestação do desejo sexual por meio da prática sexual (Butler, 2003:38).

O esporte de rendimento exige um desempenho ligado à condição física $e$, por isso, podemos supor que exista uma preocupação de que ele possa masculinizar atletas mulheres, uma vez que a feminilidade convencional não incorpora imagens de força física e musculosidade. As mulheres que praticam esporte assumem atributos do gênero masculino (em função do desenvolvimento dos músculos e da força), extrapolando as normas do seu gênero.

Ao longo da Guerra Fria, os comportamentos feminino e masculino heterossexuais "corretos" foram um importante componente da ideia ocidental de superioridade. A mídia televisiva destacava as aparências para falar da superioridade das atletas do bloco sob a órbita da URSS. Ridicularizava a desviante 
sexualidade das atletas dos países comunistas, destacando negativamente seus músculos superdesenvolvidos, elogiando, em contrapartida, a boa aparência e as formas encantadoras das atletas ocidentais que estavam em conformidade com os estereótipos heteronormativos (Guttmann, 1996). ${ }^{10}$

Durante aquele período, as mulheres ocidentais eram "belas, maternais e femininas", se podemos parafrasear Silvana Goellner (1999), simbolizando a imagem heteronormativa como unidade democrática. A democracia do Ocidente teve o apoio das noções tradicionais de masculinidade e feminilidade hegemônicas. Segundo Schweinbenz e Cronk (2010), no entanto, as medalhas obtidas pelas atletas do Leste não significaram o desenvolvimento ou mesmo uma igualdade sexual, mas, sim, autoritarismo, pois "democracia seria nunca forçar as mulheres a trocar sua feminilidade por medalhas de ouro" (Schweinbenz e Cronk, 2010:6, tradução nossa). A pressuposição generalizada era que a excelência atlética seria incompatível com a feminilidade, enquanto a heterossexualidade seria absoluta no Ocidente.

Na década de 1960, juntamente com as preocupações em torno do doping, os "testes de verificação de gênero" são implementados com o intuito de contribuir na manutenção do esporte como um território classificatório. Esse teste é um exemplo de como a dicotomia masculino/feminino é acolhida positivamente e mantida pelo esporte, visando sempre categorizar e classificar as competições. Ao testar os cromossomos sexuais das mulheres atletas, as organizações esportivas internacionais têm o objetivo de questionar o status biológico excepcional dessas mulheres que se desviam dos padrões da capacidade feminina (Kane, 1995).

10 Segundo Hargreaves (1987), as atletas que são demasiado musculosas, com seios pequenos, e que não exibem em seus corpos os sinais habituais da feminilidade convencional, apresentando sinais visuais de masculinidade, sofrem insinuações sobre sua desfeminização. E quando as polaridades de gênero, que são fortemente sustentadas no e pelo esporte de alto rendimento borram-se, as categorias femininas e masculinas são ameaçadas. 


\section{Os Testes de Verificação de Gênero}

Alguns sites oficiais de federações e confederações esportivas apresentam algumas particularidades em se tratando dos testes de verificação de gênero. Fazemos aqui uma análise de alguns discursos que constroem o sexo, o gênero e a sexualidade de atletas que rompem com o padrão social heteronormativo. Inicialmente, retomamos aspectos da história dessa política para, logo após, apresentar uma análise do material encontrado.

Os testes de verificação de gênero foram introduzidos no Campeonato Europeu de Atletismo, em Budapeste, Hungria, em 1966. As mulheres eram obrigadas a se apresentar nuas diante de um grupo de especialistas médicos ginecologistas e eram submetidas a uma inspeção genital visual (Ritchie, 2003). No mesmo ano, nos Jogos da Commonwealth (Comunidade Britânica), na Jamaica, todas as concorrentes do sexo feminino foram testadas, ou seja, foram submetidas a exames ginecológicos visuais para comprovação do sexo. Em 1967, o teste de cromossomo de sexo é introduzido e, pela primeira vez na história, uma atleta não conseguiu comprovar seu sexo. A polonesa Ewa Klobukowska passou pela inspeção visual, mas, mais tarde, foi desclassificada porque tinha um cromossomo a mais do que era permitido para que se qualificasse como mulher. A atleta tinha cromossomos XXY, e não a definição cromossômica compatível com o sexo feminino, ou seja, cromossomos XX. Mesmo que se tentasse justificar esses testes pela intenção de evitar que atletas do sexo masculino competissem em concorrência desleal com mulheres, as queixas em relação à abordagem constrangedora foram frequentes (Ritchie, 2003).

A introdução da Política de Verificação de Gênero ${ }^{11}$ pelo COI, em 1968, nos Jogos Olímpicos de Verão e nos de Inverno, foi

\footnotetext{
${ }^{11}$ Nome padrão inicialmente dado para os testes que eram feitos para comprovação do sexo, e não do gênero, das atletas como informa o próprio título da política. Em algumas federações e confederações existe uma equipe responsável pela Política de Verificação de Gênero (para casos de suspeita do
} 
publicamente anunciada como forma de garantir que todas as atletas do sexo feminino competissem em igualdade de chances. Segundo o que consta nos sites pesquisados, esse é um dos principais objetivos da política. No entanto, quando esse teste foi oficialmente retirado dos Jogos Olímpicos, em 1999, conclui-se que a comunidade internacional havia provocado somente uma grande confusão entre atletas mulheres $e$ intersexuais. ${ }^{12}$ Além disso, essa política ajudou a reforçar a divisão entre os sexos no esporte de alto rendimento, bem como a marcar a vida das mulheres que tiveram que passar por tal experiência, algumas tendo que comprovar sua condição "verdadeira" de mulher. ${ }^{13}$

As federações esportivas internacionais, em geral, foram favoráveis aos testes, com o argumento de que assim estaria preservada a autenticidade $e^{14}$ das competições femininas. $\mathrm{O}$ invasivo exame ginecológico foi substituído pelo de análise da cromatina sexual feito a partir da mucosa bucal coletada com uma lâmina e que passa por análise citológica. É um teste utilizado em

sexo dos/as atletas), composta por ginecologista, endocrinologista, psicólogo e especialista em gênero e questões transgender.

${ }^{12}$ A palavra intersexual é preferível ao termo hermafrodita e é usada para se referir a uma variedade de condições (genéticas e/ou somáticas) com que uma pessoa nasce, apresentando uma anatomia reprodutiva e sexual que não se ajusta às definições de masculino e feminino, tendo parcial ou completamente desenvolvidos ambos os órgãos sexuais, ou um predominando sobre o outro. A intersexualidade, como transgeneridade, é uma condição e não uma orientação sexual. Portanto, as pessoas que se autodenominam intersexuais podem se identificar como homossexuais, heterossexuais ou bissexuais.

${ }^{13} \mathrm{Em}$ seu texto "O verdadeiro sexo", Foucault dirá: "Precisamos verdadeiramente de um verdadeiro sexo? Com uma constância que beira a teimosia, as sociedades do Ocidente moderno responderam afirmativamente a essa pergunta. Elas obstinadamente fizeram intervir essa questão do 'verdadeiro sexo' em uma ordem de coisas na qual se podia imaginar que apenas contam a realidade dos corpos e a intensidade dos prazeres." (Foucault, 2006:82).

${ }^{14} \mathrm{~A}$ autenticidade é um termo utilizado nas teorias queer para aproximar o debate sobre as modificações corporais. A autenticidade de um corpo transformado está no processo que o fabricou, produto de criação, de intervenção, de um desejo próprio. Para mais, consultar, entre outros, Maluf (2002). 
casos em que há incerteza quanto ao sexo da atleta. A suspeita parece ser disparada quando surgem "efeitos colaterais masculinos" (porque o doping é facilmente confundido com efeitos de masculinização) que agem sobre uma feminilidade convencional ou quando há uma performance muito superior em comparação com outras atletas. Esse exame tem os mesmos fins do exame ginecológico: "detectar impostores do sexo masculino que teriam uma vantagem desleal com base na dimensão superior, força $e$ velocidade associado com massa muscular avançada dos homens" (Dickinson et al., 1984).

Num momento em que surgem dúvidas sobre a legitimidade do sexo de algumas atletas ${ }^{15}$, a comunidade internacional toma suas medidas a fim de evitar que "homens" (transexuais ou mulheres com altas doses de esteroides anabolizantes) tenham vantagem nas modalidades femininas.

Enquanto, no século XX, houve a preocupação com a preservação da feminilidade das mulheres atletas, assistimos, no século XXI, a um aumento do sucesso e da visibilidade das mulheres no esporte de alto rendimento, o que acaba aproximando-as de uma imagem masculina em suas características físicas. Corpo forte, músculos potentes $e$ avantajados são, "naturalmente", associados aos atletas homens e quando algumas mulheres apresentam esses padrões de corpos, com características marcadamente (estereotipadas como) masculinas, o gênero e o sexo delas passam a ser questionados.

Jennifer Hargreaves (1987) argumentou que os esportes têm sido apropriadamente classificados como "masculinos" $e$ "femininos" porque defendem ferozmente uma tradição heterossexista, baseada numa feminilidade convencional que não permite incorporar imagens de força física e musculosidade às mulheres atletas. Por isso, as próprias adversárias surgem como participantes no processo de manutenção dessa ordem esportiva.

${ }^{15}$ Como, por exemplo, a performance das atletas alemãs, a partir da década de 1960, que causou uma grande reação social sexista que questionava o sexo delas. A mídia, os médicos e dirigentes desportivos retomaram seus interesses nas definições biológicas da mulher. Sobre o tema, consultar Devide e Votre (2005). 
Especialistas passaram a procurar nas mulheres atletas características sexuais secundárias e anomalias cromossômicas para determinar se seriam de fato do sexo feminino, mulheres "de verdade", autênticas. Exemplo recente desse movimento diz respeito à sul-africana Caster Semenya, que com 19 anos apresentou um desempenho muito superior ao de suas adversárias durante a prova de $800 \mathrm{~m}$ no Mundial de Atletismo, em Berlim, em 2009, levantando fortes suspeitas sobre sua condição. Seu tempo foi de $1 \mathrm{~m}: 55$ s. 45 centésimos, 2.45 segundos mais rápido do que o tempo da antes campeã, a queniana Janeth Jepkosgei, o que é uma diferença considerável.

Perguntas quanto ao sexo da corredora partiram de outras atletas, de espectadores e da mídia internacional, tanto por causa de sua aparência fora dos padrões heteronormativos, quanto por suas capacidades atléticas muito superiores às das adversárias. No início, houve suspeitas de que ela houvesse ingerido substâncias dopantes, mas elas logo deram lugar a outro tipo de preocupação. Semenya foi submetida ao teste de verificação de gênero para descobrir se ela realmente seria mulher.

A mídia tratou de construir várias narrativas sobre Semenya, retratando-a ora como vítima, ora como objeto bizarro: "Caster Semenya é pseudo-hermafrodita", "A história da mulher-homem já tem barbas - São várias as atletas femininas com traços masculinos, provocados por drogas ou pela mãe natureza", "Relato de que Semenya seria 'hermafrodita' revolta o país", "Família defende atleta com feminilidade sob suspeita". Essas foram algumas das manchetes que circularam naquele momento sobre a situação vivida pela atleta. ${ }^{16}$

\footnotetext{
${ }^{16}$ As reportagens foram extraídas, respectivamente dos seguintes sites: $<$ http://desporto.publico.pt/noticia.aspx?id=1400206 $>$. Acessado em: $17 \mathrm{jul}$ 2010; < http://www1.ionline.pt/conteudo/19433-semenya-pensou-recusarmedalha-ouro $>$. Acessado em: 17 jul 2010; < http://www.estadao.com.br/noticias/esportes, relato-de-que-semenya-seriahermafrodita-revolta-pais,433293,0.htm > . Acessado em: 28 mar 2011; $<$ http://www.estadao.com.br/noticias/esportes,familia-defende-atleta-comfeminilidade-sob-suspeita,421920,0.htm>. Acessado em 28 mar 2011.
} 
Alegações de que Semenya seria hermafrodita, sem ovários e sem útero, foram espalhadas por todo o mundo. A esse respeito, a corredora posicionou-se dizendo que pouco lhe importavam as acusações, uma vez que seria, antes de tudo, uma atleta. Concluiu dizendo não se importar com o que os outros dizem quando está na pista:

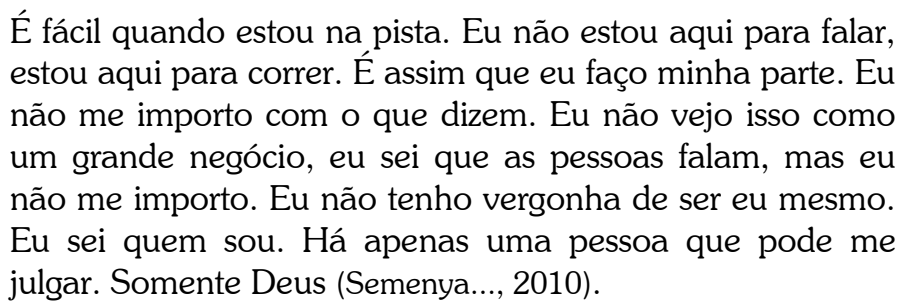

Caster Semenya recebeu a medalha de ouro, mas a Federação Internacional de Atletismo (IAAF) deixou claro que se a atleta não fosse posteriormente aprovada no teste de feminilidade, seria desclassificada, com a consequente anulação do resultado $e$ devolução da medalha. A população sul-africana saiu em defesa da atleta, que foi recebida com festa ao retornar dos Jogos, tornando-se heroína nacional, segundo noticiaram muitos jornais ("Multidão recebe corredora com identidade sexual questionada", "Atleta com gênero sob suspeita é recebida com festa", "Atleta acusada de ser homem é recebida com festa na África do Sul"). ${ }^{17}$

Observando os discursos da imprensa, podemos sugerir que uma mulher não é simplesmente aceitável por ser mulher (genitália, cromossomos, órgãos sexuais) e, sim, o é quando aparece e/ou se comporta de determinadas maneiras que vão ao encontro de uma feminilidade heterossexual. Então, o que conta como feminino? Semenya é um exemplo interessante, pois é

${ }^{17}$ As reportagens foram extraídas, respectivamente dos seguintes sites: $<$ http://noticias.terra.com.br/interna/0,,OI3940147-EI188,00.html>. Acessado em: 17 jun 2010; <http://www.estadao.com.br/noticias/esportes,atleta-comgenero-sob-suspeita-e-recebida-com-festa, $424235,0 . h t m>$. Acessado em: $10 \mathrm{mar}$ 2010; <http://www1.folha.uol.com.br/folha/esporte/ult92u614441.shtml>. Acessado em: 30 ago 2009. 
andrógina. Ela poderia ser confundida com um homem, ao não apresentar características bastante normativas de uma mulher: cabelos longos, seios visíveis, e assim por diante. Essas características necessárias para um desempenho feminino não estão presentes em Semenya. Seu tamanho, musculosidade e comportamento estão fora dos limites de um desempenho feminino visto como autêntico.

As atletas que não são convencionalmente femininas são vistas como masculinas porque é assim que são faladas na mídia. $\mathrm{O}$ investimento da imprensa contra Caster Semenya fez com que ela concedesse uma entrevista para a revista sul-africana $\mathrm{You}^{18}$, na qual aparece na capa, encenando uma performance de gênero feminina: usava vestido, maquiagem e alguns acessórios femininos. Talvez tenha sido essa a alternativa que a atleta encontrou para marcar seu gênero a partir de sua aparência, que parece ser crucial para a afirmação de sua autenticidade como mulher, criando um mecanismo para cessarem os rumores sobre a sua sexualidade.

As características esportivas, inicialmente vinculadas ao comportamento masculino, tais como força, velocidade $e$ potência, como já antes sugerido, estão dissociadas da prática das mulheres e auxiliam na manutenção de um ideário do campo esportivo como sendo dos homens. Esse contexto acabou contribuindo para que as mulheres fossem inferiorizadas em relação aos homens na prática esportiva, por pressupostos baseados na biologização das condutas. Parece-nos que a Política de Verificação de Gênero, como foi inicialmente denominada, simboliza a ideia de uma superioridade masculina, preocupada em demarcar e comprovar cientificamente que há uma distinção absoluta e insuperável entre os sexos.

18 Segundo o site da Revista You (<http://www.you.co.za/>, acessado em 02 jun 2012). "YOU tem a receita vencedora para entreter, informar e intrigar com recursos atuais sobre os acontecimentos que tocam a vida das famílias médias da África do Sul. Como parte do cotidiano dos sul-africanos de língua inglesa, YOU é a revista mais vendida no país, com pouco mais de 2,1 milhões de leitores." (tradução nossa). 
Por outro lado, esse teste mostra uma contradição: o esporte de alto nível requer, a cada dia, uma superação de performance, exigindo que as atletas sejam mais fortes, mais musculosas, mais rápidas. Ao mesmo tempo, essas mulheres precisam ser configuradas dentro dos padrões sociais heteronormativos, e com seu sexo comprovado cientificamente. Adelman (2003) levanta a questão do investimento das jogadoras de voleibol da seleção brasileira em manter a feminilidade de sua atividade em função de uma preocupação da masculinização do corpo atlético em outros esportes coletivos. As jogadoras entrevistadas em sua pesquisa apontam para uma valorização de um corpo atleta forte e sadio $e$ que seja relativamente musculoso, mas sempre feminino. Para essa autora, o esporte é hoje "um dos mais importantes espaços de conflitos relativos à definição da corporalidade feminina" (Adelman, 2003:449).

Em contrapartida, pesquisas sobre fisiculturistas vêm mostrando que as atletas estão redefinindo para si um novo padrão de feminilidade, ao invés de lutar com a heteronormatividade feminina. Ou seja, a modalidade tem servido como um espaço para a negociação de gênero por meio da aparência, da forma física e, por isso, as atletas estão redefinindo a feminilidade e desafiando as normas de gênero (Jaeger e Goellner, 2011). Segundo uma pesquisa realizada por Duff et al. (1999), mulheres fisiculturistas relatam um enorme prazer em serem fortes fisicamente. Também disseram que a força física seria necessária para a prática de esportes e que isso torna as mulheres mais femininas. Heywood (1998) reconhece que ser grande na forma física (possuir uma musculatura avantajada) está em conflito com o que seria tradicionalmente feminino, mas, fundamentalmente, interpreta as contradições da musculação como movimento para refutar suposições sobre a inferioridade do sexo feminino e sua correspondente fraqueza física. ${ }^{19}$

19 Segundo diversas pesquisas, a musculação como um esporte também seria local para a negociação de gênero por meio da forma corpórea (Bordo, 1993; Dworkin, 2003; Heywood, 1998; Lowe, 1998; Shea, 2001; Wesely, 2001). Wesely (2001) encontrou bodybuilders que atribuem um caráter mais fluído à 
Aquelas que desenvolvem músculos e força enfrentam o risco da virilização e da masculinização, entretanto, essa preocupação com a desfeminização do sexo feminino parece levar algumas atletas a reiterar que, de fato, independente da modalidade que praticam, precisam manter sua feminilidade. Isso pode ser mais bem observado por meio das roupas, acessórios $e$ penteados utilizados para a prática esportiva, que estão relacionados a uma atratividade heterossexual, reiterando a perspectiva de que uma mulher, para manter-se enquanto tal, não deve abrir mão de suas características femininas. Ou seja, se, por um lado, as mulheres atletas rompem com elementos de uma estética da limitação ${ }^{20}$; por outro, reafirmam uma cultura na qual a atividade esportiva pode comprometer sua feminilidade (Adelman, 2003). Carmen Soares (2011) pesquisou sobre as roupas de atletas na primeira metade do século $\mathrm{XX}$, mostrando como elas faziam parte de uma educação do corpo interessada em protegê-lo do olhar do outro, mas também em estabelecer marcadores sociais $e$ sexuais, representando acumulação de conhecimentos científicos e tecnológicos. A partir da análise de algumas revistas que circularam naqueles anos, a autora conclui que:

Parece haver uma ênfase sempre maior na aparência do que propriamente na eficácia de um gesto, na busca de uma performance. Se a roupa esportiva é moda, se ela dita moda e se ela prima também pelo conforto, quando é destinada às mulheres parece ainda percorrer caminhos mais lentos e mais contraditórios, revelando ambiguidades mais agudas, transitando entre a eficácia, o conforto e a simples elegância (Soares, 2011:110-111).

Nos sites pesquisados para este estudo existem muitos conteúdos relativos a política de verificação de gênero, apesar de

identidade de gênero, constituindo uma compreensão sobre seus corpos que demonstra que eles não são passivamente presos a uma identidade.

${ }^{20}$ Para saber mais sobre a feminilidade exacerbada de algumas atletas, consultar o artigo de Adelman, 2003. 
468 Doping e controle de feminilidade no esporte

não ser mais obrigatória desde os Jogos Olímpicos de 2000, realizados em Sydney, na Austrália. A IAAF (Federação Internacional de Atletismo Amador) foi uma das federações que reclamou ao COI (Comitê Olímpico Internacional) o fim desses testes, conforme explicita no Manual de Verificação de Gênero presente em seu website. ${ }^{21}$ A IAAF abandou os testes em 1991, "em função das incertezas dos métodos utilizados" (2006:1). Entretanto, ressalta no manual já citado que, "as pesquisas continuam até que se encontre uma solução aceitável e justa, a fim de ser capaz de resolver as anomalias ocasionais que surgirem." (IAAF, 2006:1).

A Política de Verificação de Gênero surge, nos sites visitados $^{22}$ e em algumas notícias coletadas ${ }^{23}$, ligada, em termos discursivos, aos processos de transexualidade (cirurgia de redesignação sexual ${ }^{24}$ ). É sempre reafirmado o discurso da vantagem que pode ser adquirida em ser homem (antes da cirurgia) e competir com as mulheres. Para especialistas da IAAF,

${ }^{21}$ No site, encontramos um manual preparado pela Comissão Médica e Antidoping da IAAF, em 2006, denominado "IAAF Policy on Gender Verification", $\quad$ (<http://www.iaaf.org/mm/document/imported/36983.pdf $>$ ). Acessado em: 03 mar 2011.

${ }^{22} \mathrm{O}$ manual da Política de Verificação de Gênero, elaborado pela Comissão Médica do COI, disponível no site da IAAF, conta com um capítulo destinado a informar como se deve proceder no tratamento de casos de ambiguidade de gênero. No anexo A do documento, encontramos uma nota explicativa sobre a readequação sexual e a participação no esporte. Como anexo $\mathrm{B}$, encontramos a Declaração de Estocolmo sobre o consenso de redesignação sexual em esportes.

${ }^{23}$ Como, por exemplo, as seguintes manchetes: "COI quer novos centros para provar o gênero de atletas" (<http://www.espbr.com/noticias/coi-novos-centrospara-provar-genero-atletas $>$ ), acessada em 08 jul 2011; "Hermafrodita ganha torneios femininos e levanta polêmica no mundo do tênis" (<http://www.espbr.com/noticias/hermafrodita-ganha-torneios-femininos-levantapolemica-no-mundo-tenis $>$ ), acessada em 08 jul 2011.

${ }^{24}$ Declaração de Estocolmo sobre o consenso de redesignação sexual em esportes.

Disponível

em: $<$ http://www.olympic.org/en/content/TheIOC/Comissions/Medical/?articleNewsGr oup $=1 \&$ currentArticlesPageIPP $=10 \&$ currentArticlesPage $=4 \&$ articleId $=56230>$. Acessada em: 03 mar 2011. 
qualquer pessoa que se submeteu à cirurgia de redesignação sexual antes da puberdade, pode ser aceita no esporte, sob o sexo escolhido. Entretanto, após a puberdade, essa questão torna-se mais complexa, pois acreditam que os homens já sofreram a influência mais decisiva dos hormônios. A puberdade masculina demarcaria uma influência da testosterona que poderia, em tese, ser de grande importância, mesmo depois de uma mudança para o sexo feminino. Compõe esse debate um "código", uma lista de requisitos para que o/a atleta possa competir sob a rubrica de gênero não dado pelo nascimento, pois o COI já permitiu a participação desses/as atletas ${ }^{25}$ em suas competições. Entretanto, ainda não existe um padrão nas ações das federações $e$ confederações em relação a essa normativa do COI.

Em 2004, o COI estabeleceu regras para que atletas transexuais pudessem ser incluídos/as em competições olímpicas, desde que comprovassem, entre outras coisas, possuir as características corporais equivalentes ao gênero em que se harmonizaram para viver. A principal preocupação do COI é que uma transexual feminina possa ter alguma vantagem sobre uma adversária. Segundo especialistas, os níveis de testosterona e a massa muscular das transexuais femininas devem baixar a planos vistos como verdadeiramente femininos, após a terapia hormonal $e$ a cirurgia de redesignação sexual. ${ }^{26}$

A Declaração de Estocolmo sobre o consenso de redesignação sexual no esporte foi formulada em 28 de outubro de 2003, por uma Comissão do COI para discutir e formular

\footnotetext{
${ }^{25}$ As primeiras atletas transexuais a ganharem certa visibilidade foram: a jogadora de futebol Martine Delaney, a ciclista Michelle Dumaresq e a golfista Mianne Bagger. Outro caso bastante divulgado foi o de um atleta de muai-thay (boxe tailandês) que, após tornar-se campeão tailandês, abandonou o esporte e passou por uma cirurgia de redesignação sexual. Este último exemplo, gerou um filme, Beautiful Boxer (Ekachai Uekrongtham, Filipinas, 2003), baseado na história real da transexual Parinya Charoenphol, conhecida como Nong Toom na Tailândia.

${ }^{26}$ Informações extraídas do documento que formulou as recomendações sobre a participação de atletas que passaram por cirurgia de mudança de sexo Declaração de Estocolmo sobre o consenso de redesignação sexual no esporte.
} 
políticas para participação no esporte de pessoas que passaram pelo processo de mudança de sexo (de homem para mulher $e$ vice-versa). Essa declaração já está em voga, entretanto, ainda não há uma padronização do tratamento oferecido à questão pelas federações e confederações. Como a Declaração não torna obrigatória a aceitação de atletas transexuais em todos os esportes, cada uma ainda atua conforme suas próprias regras.

\section{Considerações finais}

A preocupação generalizada com a des-feminização das atletas do sexo feminino passou a dominar o cenário do esporte internacional. Lenskyj (2008:86, tradução nossa) afirmou que "claramente, a ambiguidade sexual, clínico ou social, representava uma ameaça para a obrigatoriedade da heterossexualidade e a dominação masculina". O esporte torna-se campo de confronto de identidades e de gênero. Esse "transtorno" da ambiguidade deveria ser resolvido. Como? Os testes de sexo (como eram inicialmente denominados) foram introduzidos na comunidade esportiva internacional para tranquilizar todos/as os/as atletas de que as atletas do sexo feminino verdadeiramente eram mulheres!

As proibições do doping promovem uma ordem de gênero que é heterossexual, e a heterossexualidade para o sexo feminino é entendida como expressa em uma performance de feminilidade. $\mathrm{Ou}$ seja, as mulheres que estão em conformidade com a feminilidade não são tidas como lésbicas ou bissexuais, mas sim heterossexuais; e só quando uma performance de gênero é não feminina que surge a pergunta se a mulher é lésbica.

Se considerarmos que ser lésbica ou ser demasiado masculina também é parte do que está colocando em risco a ordem social heteronormativa, talvez a ameaça não seja as mulheres realmente tornarem-se homens por meio do doping, de uma cirurgia, ou seja lá de que forma. O que se torna perturbador em algumas atletas dopadas é que não existe uma estabilidade na distinção entre homens e mulheres. 
O esporte compõe um ambiente que, de forma geral, tende a não tolerar diferenças, por isso o esmero em classificar as competições destinando-as para grupos específicos, por gênero, opção sexual, idade, paraolímpicos - em várias categorias diferentes - etc. Por outro lado, faz parte do universo competitivo a produção da desigualdade, demarcada, especialmente, pelo código vitória/derrota. Além disso, embora o esporte se baseie na igualdade formal de chances, as desigualdades estão na base da preparação esportiva, o que leva Eugen König (1996) a ilegitimidade do doping: se ele é condenado em nome da igualdade de chances para todos, como conviver com as diferenças gritantes de estrutura para o treinamento corporal presentes em diferentes países? (Vaz, 2005:28).

O doping das mulheres perturba a matriz heterossexual (rompe com o trinômio sexo/gênero/sexualidade) porque as mulheres dopadas violam a feminilidade heterossexual pelos efeitos de masculinização. São duas as questões que perturbam a matriz heterossexual: o incômodo do doping em si e os efeitos que essas substâncias podem ter sobre a feminilidade convencional. Se não houver feminilidade coerente com a matriz heterossexual, e se essas mulheres deixam de ser claramente diferentes dos homens, a integridade nas categorias homens e mulheres está perturbada e aqueles que são chamados "os homens" ou "as mulheres" já não podem ter certeza do que é uma identidade estável. Qual é o lugar dessa questão na dinâmica do esporte de alto rendimento? $\mathrm{O}$ esporte de competição necessita e investe na manutenção da ordem de gênero, tendendo a uma indistinção em favor do máximo rendimento, ainda que a performance inclua um conjunto de expectativas sobre feminilidade e masculinidade. Mesmo mulheres convencionalmente femininas perturbam noções coerentes da heterossexualidade socialmente construídas quando transgridem os limites de performance masculina. 


\section{Referências bibliográficas}

ADELMAN, Miriam. Mulheres atletas: re-significações da corporalidade feminina? Revista Estudos Feministas 11 (2), Florianópolis, UFSC, 2003, pp.445-465.

ANN LOCK, Rebecca. The doping ban: Compulsory heterosexuality and lesbophofobia. International Review for the Sociology of Sport, London, Sage Publications, vol.38, nº4, 2003, pp.397-411.

ARTiOl, G. et al. Terapia gênica, doping genético e esporte: fundamentação e implicações para o futuro. Revista Brasileira de Medicina do Esporte, Niterói, Redprint, vol.13, n5, set/out 2007, pp.349-354.

BEAMISH, Rob; RITCHIE, Ian. From chivalrous 'brothers-in-arms' to the eligible athlete: Changed principles and the IOC's banned substance list. International Review for the Sociology of Sport, London, Sage Publications, vol.39, n²4, 2004, pp.355-371.

BORDO, Susan. Unbearable Weight: Feminism, Western Culture and the Body. Berkeley, University of California Press, 1993.

BUTLER, Judith. Cuerpos que importan: sobre los limites materiales y discursivos del "sexo". Buenos Aires, Paidós, 2002.

. Problemas de gênero: feminismo e subversão de identidade. Rio de Janeiro, Civilização Brasileira, 2003.

CAHN, Susan. Coming on strong: Gender and sexuality in twentiethcentury women's sport. New York, The Free Press, 1994.

ChILAND, Colette. O transexualismo. São Paulo, Loyola, 2008.

CONNELL, Robert. Gender and power. Stanford, Stanford University Press, 1987.

CONNELL, Robert. Making gendered people: Bodies, identities, sexualities. In: FERREE, Myra; LORBER, Judith; HESS, Beth (Ed.). Revisioning Gender. Thousand Oaks, Sage, 1999, p449-471.

ConNell, Robert. Gender. Cambridge, Polity Press, 2002.

DE ROSE, Eduardo Henrique et al. Controle antidoping no Brasil: resultados do ano de 2003 e atividades de prevenção. Revista 
cadernos pagu (42) Viviane Teixeira Silveira e Alexandre Fernandez Vaz 473

Brasileira de Medicina do Esporte, Niterói, Redprint, vol.10, nº , jul./ago. 2004, pp.289-293.

DEVIDE, Fabiano Pries; VOTRE, Sebastião José. Doping e mulheres nos esportes. Revista Brasileira de Ciências do Esporte, Campinas, CBCE/Autores Associados, vol.27, nº1, set/2005, pp.123-138.

DICKSON, Barry et al. Gender verification of female olimpic athlets. Medicine \& Science in Sports \& Exercise, Philadelphia, Churchill Livingstone, vol.34, n¹0, 2002, pp.1539-1542.

DUFF, Robert; HONG, Lawrence; ROYCE, Stephen. Gender comparisons in weight training for collegiate sports. Gender Issues, Boston, Springer, vol.17, n4, 1999, pp.74-85.

DWORKIN, Shari. Holding back: Negotiating a glass ceiling on women's muscular strength. In: WEITZ, Rose (Ed.). The politics of women's bodies: sexuality, appearance, and behavior. New York, Oxford University Press, 2003, pp.240-256.

Foucault, Michel. Ética, Sexualidade, Política. Ditos e Escritos, vol. 5. Rio de Janeiro, Forense Universitária, 2006.

GOELLNER, Silvana. Bela, maternal e feminina: Imagens da mulher na Revista Educação Physica. Tese de Doutorado em Educação, Faculdade de Educação, Unicamp, 1999.

GRIFFIN, Pat. Strong women, deep closets: Lesbians and homophobia in sport. Champaign, Human Kinetics, 1998.

GuTTMANN, Allen. The game must go on: avery brundage and the olympic movement. New York, Columbia University Press, 1984.

1996.

. Sports Spectators. New York, Columbia University Press,

HARAWAY, Donna. Manisfesto cyborg: ciência, tecnologia e feminismsocialista no final do século XX. In: SILVA, Tomaz Tadeu. Antropologia do ciborgue: as vertigens do pós-humano. Belo Horizonte, Autêntica, 2000, pp.33-118.

HARGREAVES, John. The body, sport and power relations. In: JARY, David \& TOMLINSON, Alan (Eds.). Sport, leisure and social relations. London, Routledge \& Kegan Paul, 1987, pp.139-159. 
474 Doping e controle de feminilidade no esporte

HEYWOOD, Leslie. Bodymakers: A cultural anatomy of women's bodybuilding. New Brunswick, Rutgers University Press, 1998.

JAEGER, Angelita; GoELLNER, Silvana. O músculo estraga a mulher? A produção de feminilidades no fisiculturismo. Revista Estudos Feministas vol.19, n³, Florianópolis, UFSC, set/dez 2011, pp.955-975.

KANE, Mary Jo. Resistance/transformation of the oppositional binary: Exposing sport as a continuum. Journal of Sport and Social Issues, Champaign, Sage Publications, vol.19, n², 1995, pp.191-218.

KNIJNIK, J.D.; MACHADO, A.A. Bailarinos do esporte: notas sobre novas masculinidades em campo. In: ROMERO, Eliane; PEREIRA, E.G. (Org.). Universo do corpo: Masculinidades e feminilidades. Rio de Janeiro: SHAPE/FAPERJ, 2008, pp.153-161.

KÖNIG, Eugen. Criticism of doping: The nihilistic side of technological and the antiquated view of sports ethics. International Review for the Sociology of Sport, London, Sage Publications, vol.30, $\mathrm{n}^{\circ} 3-4$, set/1995, pp.247-260.

LENSKYJ, Helen Jefferson. Olympic industry resistance: challenging Olympic power and propaganda. Albany, State University of New York Press, 2008.

LOWE, Maria. Women of steel: Female body builders and the struggle for self-definition. New York, New York University Press, 1998.

MALUF, Sônia. Corporalidade e desejo: Tudo sobre minha mãe e o gênero na margem. Revista Estudos Feministas, vol.1, Florianópolis, UFSC, 2002, pp.143-153.

MARKULA, Prikko. The technologies of the self: Sport, feminism, and Foucault. Sociology of Sport Journal, Champaign, Human Kinetics, vol.20, 2003, pp.87-107.

MESSNER, Michael. Taking the field: Women, men, and sports. Minneapolis, University of Minnesota Press, 2002.

MIAH, Andy. Atletas geneticamente modificados. São Paulo, Phorte, 2008.

MorTON, Alexander; STOCKTON, Gwendolyn. Methylphenidate abuse and psychiatric side effects. Primary Care Companion - Journal Clinical Psychiatry, Rockville, Physicians Postgraduate Press, 2 (5), 2000, pp.159-164. 
cadernos pagu (42) Viviane Teixeira Silveira e Alexandre Fernandez Vaz 475

PRECIADO, Beatriz. Texto Yonqui: sexo, drogas e biopolítica. Madrid, Espasa-Calpe, 2008.

RITCHIE, Ian. Sex tested, gender ferified. Controlling female sexuality in the age of containment. Sport History Review, Califórnia, Human Kinetics, vol.34, n¹, 2003, pp.80-98.

SCHMOLINSKY, Gerhardt. Atletismo. Lisboa: Estampa, 1982.

SCHWEINBENZ, Amanda Nicole \& CRONK, Alexandria. Femininity Control at the Olympic Game. Thirdspace - Gender, sport and the Olympic special issue, 9/2, 2010. Disponivel em: <http:/www.thirdspace.ca/journal/article/view/schweinbenz/309>. Acesso em: 23 set 2010.

SEMENYA diz não se importar com os rumores sobre gênero. Estadão, 25 jan 2011. Disponível em: <estadao.com.br> . Acesso em: 04 out 2011.

SHEA, Christine. The paradox of pumping iron: Female bodybuilding as resistance and compliance. Women and Language, Michigan, University Michigan, vol.24, n², 2001, pp.42-46.

SOARES, Carmen Lucia. As roupas nas práticas corporais e esportivas: a educação do corpo entre o conforto, a elegância e a eficiência (19201940). Campinas: Autores Associados, 2011.

VAZ, Alexandre Fernandez. Doping, esporte, performance: notas sobre os "limites" do corpo. Revista Brasileira de Ciências do Esporte, Campinas, CBCE/Autores Associados, vol.27, nº1, out/2005, pp.23-36.

WESELY, Jennifer. Negotiating gender: Bodybuilding and the natural/unnatural continuum. Sociology of Sport Journal, Toronto, Human Kinetics, vol.18, n², 2001, pp.162-180. 